\title{
EL PENSAMIENTO DE JUAN VALLET DE GOYTISOLO Y LA ÚLTIMA TEORÍA JURÍDICA ANALÍTICA ANGLOAMERICANA"
}

\author{
Cristóbal Orrego Sánchez ${ }^{1}$
}

SUMARIO: Introducción. 1. La recepción de la teoría clásica de la ley natural. 2. Principios ético-juridicos y naturaleqa de las cosas. 3. La critica de otras concepciones sobre los "principios" en el Derecho. 4. Los principios tradicionales de cada país. 5. Principios de la ley naturaly derechos humanos. 6. Conclusión.

\section{INTRODUCCION}

Desde hace unos treinta años que la teoría analítica del derecho en el mundo de lengua inglesa da una notoria importancia a la discusión del tema de los principios (morales y políticos) en su relación con el derecho y con el razonamiento jurídico. Los que de alguna manera abordamos el estudio de la teoría jurídica analítica desde una perspectiva externa - en concreto, desde la filosofía jurídica española e hispanoamericana - no podemos dejar de sorprendernos por el aire de "novedad" que en ese ámbito tiene el descubrimiento de verdades muy clásicas, algunas de ellas magistralmente expuestas en el siglo XX por pensadores españoles. Por eso, me ha parecido de interés para los estudiosos de habla castellana, que se nutren también de los excelentes desarrollos de origen anglosajón, rescatar de un posible olvido el pensamiento de Juan Vallet de Goytisolo sobre los principios y su función en el razonamiento jurídico y, más en general, en la conformación del derecho vigente. Desde la partida debo decir que aquí el interés no es sola ni principalmente en Vallet de Goytisolo, sino en asentar una tesis más amplia, a saber, que el desconocimiento de la literatura iusfilosófica hispánica en el mundo angloamericano es causa de que nuestros colegas de lengua inglesa "descubran" con sofisticados argumentos, a veces como desafiando una tradición establecida en ese ámbito- lo que en otras partes del mundo (España y América) es sabido desde

\footnotetext{
'Profesor de Filosofia Juridica y Política, Universidad de los Andes.

${ }^{1}$ En España, el mejor estudio que conozco que aborda esta cuestión desde la perspectiva analítica es el de Nifonso GARCIA FIGUEROA, Principios y positivismo jurídico. El no positivismo principialista en las teorias de Ronald Dworkin y Robert Alexy, Centro de Estudios Politicos y Constitucionales, Madrid, 1998. Aunque se centra en estos dos autores, presenta adecuadamente el contexto de la discusión. Lamentablemente, el autor prácricamente no ciła las obras de autores anglosajones iusnaturalistas que se han referido al tema (v.gr., John FINNIS en Oxford y Robert GEORGE en Princeton), ni menos las muy valiosas de otros autores de lengua española (v.gr., Ollero, conocido en Alemania y América por sus escritos sobre "jurisprudencia de principios". o IIERVADA, con su importante puesta al día de la tradición iusnaturalista). EI autor toma la famosa obra de Giorgio DEL VECCHIO como precedente en la línea de la "tradición iusnaturalista"
} 
antiguo. Aunque podría haber aprovechado el pensamiento de otros autores españoles, que sostienen tesis parecidas sobre la función de los principios en el razonamiento jurídico, he preferido al que me parece ser el más tradicional de todos en sus formulaciones (incluso "tradicionalista", sin darle a la expresión un matiz despectivo), para hacer más fuerte la constatación de las coincidencias con los desarrollos analíticos recientes ${ }^{2}$. En consecuencia, me centro en la exposición de Vallet de Goytisolo, mencionando algunos contrapuntos del ámbito anglosajón.

\section{La recepción de la teoría clásica de la ley natural}

Vallet de Goytisolo recoge la doctrina tomista de la ley natural y sus primeros principios, que en el ámbito angloamericano ha sido expuesta, a los teóricos analíticos del derecho, por intermedio de John Finnis. Tomás de Aquino distinguía entre los primeros principios de la razón especulativa y los primeros principios de la razón práctica, "diferenciándose unos y otros principios en que los de la razón especulativa sirven para hallar y conocer la verdad; y los de la razón práctica se dirigen al bien obrar. Denominó a estos primeros principios de la ley natural"4. Ahora bien, Vallet de Goytisolo procura relacionar su recepción activa de la doctrina tradicional con los nuevos desarrollos de la ciencia jurídica continental - desconocidos también hasta hace poco en el ámbito angloamericano-, por lo que incluye en los principios prácticos de Tomás de Aquino "tanto los que Karl Larenz denomina principios ético-juridicos como los que denomina criterios teleológicoobjetivos. Éstos dimanantes de la naturaleza de la cosa y aquéllos de su puesta en relación, entre sí y con esa naturaleza de la cosa considerada como criterio teleológico-objetivo. Por eso mismo, no deben ser objeto de deducciones sino de concretizaciones, como expresa el propio Larenz siguiendo la terminología muy expresiva iniciada por Walter Schönfeld y explicada por Karl Engisch" "5.

No obstante, Vallet de Goytisolo advierte que la expresión "principios generales del derecho" ha sido el sustitutivo de la idea de derecho natural, necesaria para toda ciencia jurídica que no quiera quedar prisionera de la rigidez histórica de las reglas positivas, especialmente si son codificadas. Cuando Tomás de Aquino formula el primer principio de la razón práctica ("se ha de obrar y proseguir el bien y evitar el mal" (S. Th, I-II, 94, 3)) y cuando Ulpiano expone los preceptos de derecho ("Iuris praecepta sunt baec: honeste vivere, alterum non laedere, summ inique tribuendl"

\footnotetext{
${ }^{3}$ Vid. especialmente FINNIS, John; Natural Law and Natural Rights, Oxford University Press, Oxford, 1980. Hay traducción castellana de Cristóbal Orrego: John FINNIS, Ley natural y derechos naturales, Abeledo-Perrot, Buenos Aires, 2000 .

"Cf, ibid, 348. Esta opinión se vio reflejada luego en la doctrina civilista sobre el valor de los principios generales del derccho. cf. ibid. 350-351.
} 
(Dig., párrafo 1)) expresan principios muy generales. Por eso, "los principios generales del derecho no concluyen aquí. Casi diría que de ahí arrancan; es decir, éstos son sus presupuestos sobre cuya base comienza, propiamente, su elaboración jurídica. En su desarrollo, cada pueblo en el transcurso de su historia, los va adecuando a sus diversas circunstancias de situación geográfica, climática y militar, comercial, económica, social, a sus aptitudes, clima moral, género de vida, etcétera, etc.; los va forjando y, a veces, proclamando de uno u otro modo. Y, en su decurso histórico, los conserva o modifica en su tradición viva $y$, a veces, se le desvanecen a medida que pierden su ser o lo cambian por propia transformación o por asimilación a otros pueblos. Estos principios elaborados en la historia son también generales, pero no de ámbito universal sino del propio pueblo de que se trate"

Puede decirse, entonces, que los principios elaborados a partir de los primeros principios de la ley natural no tienen por qué tener la misma universalidad; por el contrario, en ellos se darán características propias del derecho positivo, como su razonable variación según tiempo y lugar. Más aún, "la formación de instituciones jurídicas, cada una de ellas o un conjunto de determinadas ramas jurídicas han ido mostrando unos principios peculiares de cada una o de cada conjunto o rama", por lo que se habla de principios del derecho civil y mercantil, y, dentro del primero, de los principios del derecho sucesorio, etc. ${ }^{9}$.

En el ámbito analítico, especialmente John Finnis y Robert P. George han recogido la tesis de la derivación de principios más concretos a partir de los primeros principios de la ley natural, no por deducción sino por determinación entre alternativas razonables abiertas ${ }^{10}$.

\footnotetext{
7 VALLET DE GOYTISOLO; idem, 353.
}

${ }^{8}$ Ibidem

?Vid. VALLET DE GOY'TISOLO, Juan; Metodologia juridica, Civitas, Madrid, 1988, 109-110: "La perspectiva de los principios jurídicos que antes hemos tratado de contemplar nos lleva a distinguir:

1." Unos principios permanentes del derecho, en su esencia más general, que se obtienen con el saber común o con el filosófico.

2." Otros principios jurídicos, propios de cada pueblo a través de la historia; que éste va forjando y adecuando, que conserva o que se desvanece. Pueden referirse a derechos que no son sino historia pasada o a derechos vivos que suceden en una tradición que continúa. Son también generales, pero no en un ámbito universal, sino en el propio del pueblo de que se trate.

3. ${ }^{\circ} \mathrm{Y}$ otros referidos a cada institución jurídica, o a un conjunto de instituciones de una determinada rama del derecho. Asi se ha hablado de distinguir los principios del derecho civil y los del derecho mercantil; se han enumerado principios del derecho sucesorio; se han señalado principios que, aun afectando a varias distintas ramas del derecho o incluso a todas, vienen a crear determinados criterios inspiradores, como los de la buena fe, abuso del derecho, enriquecimiento injusto, de no ir en contra de los actos propios, etc.".

Aparte de la ya citada obra, la exposición más al dia, aplicada a diversas áreas del derecho, está en john FINNIS, "Natural Law: The Classical Tradition", en Jules Coleman y Scott Shapiro (eds.), The Oxford Handbook of Jurisprudence and Philosophy of Law, Oxford University Press, Oxford, 2002, 1-60. De George, ver especialmente Robert P. GEORGE, In Defense of Natural Law, Oxford University Press, Oxford, 1999. 


\section{Principios ético-jurídicos y naturaleza de las cosas}

Vallet de Goytisolo considera que la ley natural es prejurídica, en cuanto que lo propiamente jurídico requiere de una concreción. En efecto, "la ley natural primaria constituye un primer dato, previo a la labor propiamente juridica" "1". Así, "sólo cabe estimar jurídica la ley natural en cuanto pueda ser recibida (...) por la ley humana o aplicada por jueces y tribunales. Esto muestra el lindero - como ya hemos visto - que delimita cuando la ley natural sólo es ética y cuando, además, es jurídica. El mismo Santo Tomás viene a expresarlo (...); y, asimismo, recordamos que Recasens Siches, resumiendo y explicando la doctrina de Francisco Suárez, señala que ésta alberga 'una distinción entre ley natural moral y ley natural jurídica'. Ésta 'sería aquella parte de la ley natural que puede ser contenido del derecho positivo" $"$,

Tras los principios primarios y secundarios de la ley natural, existen "Ios preceptos de tercer grado, o conclusiones más lejanas o remotas de los primeros principios de la ley natural, y correlativamente, el derecho natural terciario o de tercera instancia" "13, e incluso un cuarto grado, ya no de principios, sino de concretizaciones: "el derecho natural, como arte de lo justo, no se puede circunscribir solamente a la aplicación de la ley natural, ni siquiera incluyendo en ésta las normas de tercer grado, sino que desciende más a lo concreto, por lo cual podemos aún señalar en él un cuarto grado en el cual lo justo se adecúa a las circunstancias más singulares y excepcionales, pues 'o que es natural al hombre puede algunas veces fallar' (II-II, q. 57, a. 2, ad. 1 y I-II, q. 97, a. 3) y, en esos supuestos, debe recurrirse a la equidad; pues de lo contrario, 'se iría contra el derecho natural' (II-II, q. 60, a. 5, ad. 2). (...) La naturaleza de la cosa, atendida la apreciación prudencial de las circunstancias concurrentes, puede mostrar que un caso en concreto escapa de la ley aun siendo ésta naturalmente justa en sus términos generales. Lo justo natural, por lo tanto, exige salirse de esos términos generales, para que la solución individualizada sea la más adecuada examinando la cosa en relación a sus consecuencias más específicas y concretas" ${ }^{\text {"14 }}$.

\footnotetext{
11 VALLET DE GOYTISOLO; Metodologia de las leyes, 379. En el mismo sentido, Juan VALLET DE GOYTISOLO, "Observaciones de orden metodológico en torno de la concepción del derecho natural de Santo Tomás de Aquino", Anales de la Real Academia de Jurisprudencia y Legislación, 3, 1975, 25-43, reproducido en VALLET DE GOYTISOLO, Juan, Estudios sobre fuentes del derecho y método jurídico, Editorial Montecorvo, Madrid, 1982, 770 : "Nos atrevemos a insinuar, atendidas estas explicaciones del Aquinatense, que lo calificado de derecho natural primario es algo previo metajurídico, pues - como Gayo, Digesto, 1.1, 9- Santo Tomás, en la misma respuesta, observa que es común a nosotros y a los otros animales - aunque el juicio sỏlo sea nuestro-. Corresponde, pues, a la naturaleza de las cosas, que es prejuridica, aunque el derecho no pueda desconocerla, sino que ha de tenerla siempre en cuenta en sus conclusiones".

${ }^{12}$ VALLET DE GOYTISOLO; Metodologia de las leyes, 380 .

13

VALLET DE GOYTISOLO, Juan; "Las fuentes del derecho según Santo Tomás de Aquino", Anuario de Derecho Foral I, Pamplona 1975, 31-63, ahora en VALLET DE GOYTISOLO, Juan, Estudios sobre fuentes del derecho y método juridico, 231

Ibid. 233
} 
Los principios ético-jurídicos y su concreción son extremadamente importantes en una concepción del arte del derecho "que concibe la regla de derecho, no tanto como el medio de dirigir una conducta, sino más bien como un intento de buscar el derecho natural, esto es, lo naturalmente justo; por lo cual las normas no pueden sino colocar jalones, aportar indicaciones fragmentarias que, entre otras, deberán ayudar a descubrir lo justo, puesto que lo escrito no puede abarcar todo lo justo natural, que por esencia, es inexpresable en su plenitud"15.

La concepción clásica entronca con la tendencia renovadora de la teoría analítica del derecho, que, como se ve en el caso de Ronald Dworkin, también concibe la labor del jurista y del juez no como una mera interpretación y aplicación de reglas, sino como la búsqueda de la solución justa, aquella que respeta los derechos preexistentes de las personas ${ }^{16}$.

De la concepción del derecho como búsqueda de lo justo concreto, se sigue su concepción de la función judicial, la cual, en la búsqueda de tal concretización, debe aplicar la equidad en los casos en que los preceptos generales, al ser aplicados, produzcan una situación injusta. "Es pues, preciso en estos casos rectificar la conclusión. Precisamente en esto consiste lo que Aristóteles denominó epiqueya $\left[\mathrm{sic}^{17}\right]$ y los romanos tradujeron por equidad. Pero es preciso depurar esta última palabra de la penetración de otro concepto más lato de equidad, consistente en un trato benévolo, atendidas las circunstancias personales, que es fuente de inseguridad jurídica y concede, a la vez, excesiva libertad al juez, dejándole indefenso frente a las presiones, en especial las políticas" ${ }^{\text {"18. }}$

Vallet de Goytisolo contrapone dos concepciones de la función judicial, la de "guardadora del texto de las leyes positivas" y la de "defensa de lo justo concreto" " ¿Cómo no hacer, también aquí, el paralelismo con la contraposición dworkiniana entre el derecho como integridad, que busca la solución justa,

\footnotetext{
15

VALLET DE GOYIISOLO, Juan; "El derecho natural como arte juridico", Discurso de clausura de las I Jornadas Hispánicas de Derecho Natural, Madrid, 15 de septembre, publicado en El Derecho natural hispánico, Madrid, Escelicer, 1973, 465-492, ahora en Estudios sobre fuentes del derecho y método jurídico, 726.

${ }^{16}$ Cf. DWORKIN, Ronald; Los derechos en serio, Ariel, Barcelona, 1984, passim.

17

18 in realidad, debe decirse epieiqueia.

${ }^{18}$ VALLET DE GOYTISOLO, Juan; "El método clásico del derecho natural contrastado en su aplicación, a través de los juristas catalanes", Anales de la Real Academia de Jurisprudencia y Legislación, 8, 1980, 95-142, ahora en Estudios sobre fuentes del derecho y método juridico, 1006-1007. Aquí se explica el concepto de lo equitativo según Tomás de Aquino: "Es decir, lo equitativo es lo justo concreto discernido por el método de hallazgo propio de lo justo natural, ya sea buscándolo para suplir lo justo legal (cuando alguna ley humana falla), si con éste no se solucione el caso propuesto, 0 bien si su solución contradice lo justo natural; $\mathrm{o}$, incluso también, para interpretar lo justo legal de acuerdo con lo que resulte naturalmente justo en el caso concreto que se trate de resolver. Por tanto, aplicar la equidad es seguir el método hallazgo de lo justo natural para solucionar justamente un caso concreto, ya sea al margen, ya sea en contra de la ley humana, o bien guiando la interpretación de ésta. Es consecuente que, para el $\Lambda$ quinatense, la aplicación de la equidad requicre la búsqueda de lo justo natural, en cada caso concreto y atendidas: la cosa absolutamente en sí misma, y con sus consecuencias dimanantes ( . Th. I1-II, q. 57, a. 3), en relación a las exigencias del bien común, habida cuenta de lo que sea útil para la salud pública (S. Th., I-II, q. 96, a. 6, y II-II, q. 60, a. 5)".

VALLET DE GOYTISOLO; "El derecho natural como arte juridico", 727.
} 
coherente con un razonamiento jurídico orientado tanto por principios morales como por reglas, y el derecho como mero "conjunto de reglas" que dan un margen de discrecionalidad al juez? $?^{20}$. Al mismo Dworkin no le importa que a esto se le llama "ley natural" 21. Los autores analíticos como Hart o Raz, que procuran defender al menos una forma de positivismo jurídico, no se oponen a las tesis de fondo: solamente objetan la confusión que implicaría llamar "derecho" a esos otros estándares aplicados por los jueces ${ }^{22}$. Una cuestión meramente semántica.

Hernández Gil comenta que "en la concepción tomista de Vallet de Goytisolo no hay, como en la doctrina del derecho natural clásico de Villey, una total deslegalización y cosificación del derecho natural. Éste, según Vallet de Goytisolo, está formado por los principios universales de justicia enunciados como ley natural y por lo justo natural tal como lo muestran las cosas mismas. Consiguientemente, el derecho natural, si bien tiene en la ley uno de sus modos de manifestarse y de realizar la justicia, no se agota en la ley, sino que también se manifiesta en lo justo natural por sí mismo. Esta doble versión - legal y extralegal- del derecho natural está presente asimismo al proyectarse en el derecho de gentes y el civil. También en estos sectores del orden jurídico, además de leyes positivas derivadas próxima o remotamente del derecho natural, se plantea el problema de discernir lo justo natural" ${ }^{23}$. En consecuencia, la concreción de lo justo natural exige conjugar armónicamente los criterios racionales generales (ley natural) y las exigencias concretas de la naturaleza de las cosas.

\section{La crítica de otras concepciones sobre los "principios" en el derecho}

Vallet de Goytisolo critica, desde su doctrina de los principios ético-jurídicos, que procura fundamentar en la de Tomás de Aquino, algunas de las elaboraciones doctrinales alternativas más influyentes en su época.

En primer lugar critica la Wertungjurisprudenz o "jurisprudencia valorativa alemana", que se diferenció de la Interessenjurisprudeñ o "jurisprudencia de intereses", en cuanto ésta resolvía los conflictos de intereses conforme a las estimaciones resultantes de las normas legales positivas, mientras la nueva

\footnotetext{
${ }^{20}$ Vid. DWORKIN, R; Law's Empire, Fontana Press, London, 1986, trad. cast. de Claudia Ferrari, El impeno de la justicia, Gedisa, Barcelona, 1988.

${ }^{21}$ Véase DWORKIN, R.; "Natural Law Revisited", University of Florida Law Review 34, 2, 1982, 165 ss.

${ }^{22}$ Véase especialmente el Postscript de HART a The Concept of Law: H. L. A. HART, The Concept of Law, Oxford University Press, Oxford, $2^{a}$ ed., a cargo de Penelope A. Bulloch y Joseph Raz, 1994. Raz ha sido claro también en accptar la función de los principios morales en la judicación, sólo que por una cuestión meramente terminológica prefiere seguir llamando "derecho" solamente a las normas que tienen una fuente social. Cf. especialmente Joseph RAZ, The Concept of a Legal System. An Introduction to the Theory of Legal System, Oxford University Press, Oxford, 1970), 2x ed., 1980, y The Authority of Law. Essays on Law and Morality, Oxford University Press, Oxford, 1979, reimp. 1983.

23

HERNÁNDEZ GIL, Antonio; Itinerarios del Derecho Natural, en Obras Completas, tomo I, Espasa-Calpe, Madrid, 1987,159 .
} 
jurisprudencia valorativa reconoció "principios de valoración y criterios de ordenación, reconocidos y jerarquizados en la conciencia social, que no son creados por el legislador, que - como destaca Maihoffer - ha de ajustarse a ellos y que, por lo tanto, no deben su obligatoriedad al hecho de haber sido expresados más o menos claramente en la ley, según subraya Esser" ${ }^{34}$. Con esta corriente se abre la ciencia jurídica alemana a los principios éticos, y es - a nuestro modo de ver- un auténtico progreso en el sentido que mucho más tarde seguiría la jurisprudencia analítica anglosajona.

Sin embargo, nuestro autor estima que existe un problema fundamental de la jurisprudencia valorativa: "el método de esa dirección es dualista: idealista al razonar los principios supralegales, hallados por intuición y la constelación de valores jerarquizados según la conciencia social, y realista en el ámbito, inferior a dichos principios, donde la respuesta debe darla la naturaleqa de las cosas. Es de advertir que así, en el plano de los principios, entramos en una tópica de valores que no puede tener otra pretensión sino la de ser una de tantas, pues proceden de la mente, de fuera de las cosas, no corporeizados en la naturaleza, pues el valor lo asigna la mente o la conciencia social, ya que la naturaleza de las cosas no alude 'sino al sentido establecido y expresado ya en las relaciones de la vida como tales, a su estructura, teleológico-objetiva, de ahí inferidas'; pues esa naturaleza de las cosas, que es entendida en sentido mucho más restringido que la natura rei tomista, no puede configurar una escala total ${ }^{325}$.

Refiriéndose específicamente al dualismo de Stammler y al trialismo de Radbruch, sostiene nuestro autor que "hemos hablado repetidamente de la doble dirección del conocimiento y la estimativa que, en un sentido, va de nuestra inteligencia a las cosas y a los hechos que percibimos y, en el inverso, de los fenómenos captados por los sentidos a nuestra inteligencia. Este ir y venir, produce una interacción enriquecedora, que dota de mayor agudeza tanto a nuestras percepciones y estimaciones como a nuestros juicios, y, gracias a ella, observamos con más claridad y mayor inteligibilidad los fenómenos y cuantos hechos captamos. La falta de ese continuo ir y venir, de la cosa a la mente y de la mente a la cosa, caracteriza al dualismo metódico neokantiano y a la dialéctica neohegeliana" "El primer intento de la ciencia del derecho alemán por salir del positivismo fue dado, en el neokantismo de la escuela de Marburgo, por Stammler, a partir del pensar científico fin-medios, concibiendo el concepto de forma de la conciencia pensante sometida en derecho a la exigencia de rectitud, como medida superior de la idea del derecho. Pero - como nota Coing- la idea del derecho justo no tiene aún, en ese intento, sino relevancia formal y sólo es indicativa de si un determinado derecho

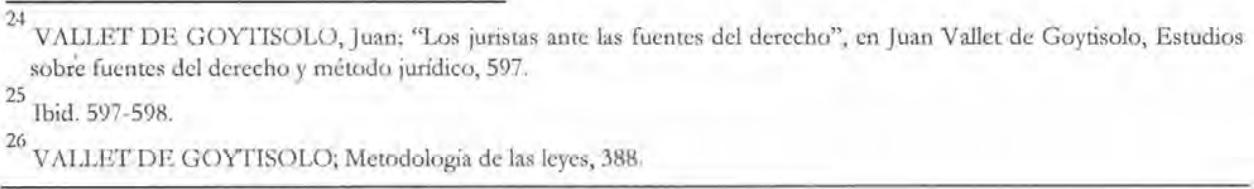


tuene su contenido en armonía con sus propias ideas fundamentales. En efecto, el propio Stammler dice que las formas puras de las nociones de derecho no son precisamente algo innato en el hombre; no gozan de una existencia aparte. Sólo se manifiestan dentro de un derecho históricamente condicionado, y se le revelan a cada individuo en los hechos concretos de su vida jurídica'. Es más, a su juicio, la idea del derecho no pasa de la aspiración de 'poner una absoluta armonía en la totalidad de las voluntades, ya definidas conceptualmente'; es 'una noción ideal, que jamás se podrá ver realizada en su total alcance'. Esto resulta concorde con la tesis kantiana 'según la cual (...) el derecho es la 'libertad externa' del hombre, es decir, una libertad que tiene que posibilitar la decisión moral autónoma del hombre?, ",27

En sintesis, el dualismo metódico de Stammler y el trialismo de Radbruch son acusados de relativismo, cuestión con la que, por lo demás, esos autores concordarian, especialmente si se les comparase con una concepción demasiado racionalista del derecho natural ${ }^{28}$.

En seguida, nuestro autor dirige sus críticas al iusnaturalismo de Coing. Radbruch había distinguido, dentro del campo jurídico, tres valores: la justicia, la conformidad al fin y la certeza. Coing concibe una lucha en el ámbito jurídico entre la justicia y la seguridad. En cambio, Vallet de Goytisolo - en esto concuerda con Michel Villey - sostiene que en el arte jurídico el único "valor" que existe es la justicia. Sucede que la justicia, entendida de manera clásica, incluye, a su manera, la certeza: cuando se dice que "prima la seguridad" por sobre la justicia (v.gr., en instituciones como la prescripción), en realidad prima el bien común, que es exigencia de la justicia general, por sobre alguna relación de justicia particular ${ }^{29}$.

27

Ibid. $386-387$

${ }^{28}$ La exposición sobre STAMMI.ER y RADBRUCH puede verse en ibid. 388 ss.

29

Ibid. 399. Respecto a este derecho natumal "de valores" se puede citar la critica de Spaemann, que se refiere a la filosofia subjetivista de los valores (no racionales); "¿Qué es, sin embargo, lo buscado? Cuando la disputa por el derecho es uno de los argumentos más fuertes a favor del derecho natural, entonces debe ser contemplada con escepticismo una determinada mancra de pensamiento 'iusnaturalista', que en los últimos 25 años ha jugado un papel predominante sobre todo en la filosotia del derecho alemana: aquélla que trabaja con los conceptos 'valor' y 'orden de valores', los que son colocados como 'normas' frente a la realidad social. Con el concepto del 'valor' se pone término a la disputa; con él se apela a una última evidencia, una 'intuición del valor' (Werteinsicht), un 'sentimiento del valor' (Wertfühlen), que ya no es más susceptible de mediación discursiva, sobre la cual tampoco puede discutirse. Ya Platón, el padre de la doctrina clásica del derecho natural, conocía una cvidencia última, no mediable: cl examen de la idea del Bicn. Pero esta Idea, que señala el último fundamento de nuestro ser y actuar, es, en primer lugar, no una sustancia (Gehalt) material, sino que, en esta perspectiva, una 'fórmula vacia' - como críticamente se ha opuesto desde Aristóteles hasta Topitsch-; y, en scgundo lugar, a ella no sc apcla como a un inmediato, sino que resulta, se enciende la luz repentinamente como por chispas de fuego', al final de un largo camino discursivo de superaciones dialécticas. El recurso a valores materiales, pensados como unos incondicionalmente válidos, se muestra como lo contrario (...). Con ello no se ha expresado nada sobre el enfoque teorético de la filosofia de los valores. Max Scheler mismo había visto que las estructuras de valores apriorísticas contempladas fenomenológicamente no eran relevantes inmediatamente como tales para un sistema cultural de normas y del derecho. Cada sistema tal, cada Ethos histórico está determinado para él mucho más por una perspectiva histórica determinada por aquel reino de valores. La filosofia del derecho puede entonces, cuando argumenta axiológicamente, tener relación sólo con esta perspectiva, (...) una configuración especifica, un 'perspectivismo axiológico' especifico. En esta área no cumple el enfoque filosôfico de valores, sin cmbargo, lo que debe realizar. La referencia a algo asi como un 'orden de valores occidental' o al 'sistema de valores subyacente en nuestra Constitución' no es menos relativista y positivista que la referencia al tenor literal de las leyes. Sirve sólo para conceder mayor independencia al juez como legítimo intérprete de tal sistema de valores frente al legishador, fomenta la evolución 
Finalmente, nuestro autor se refiere a los modelos constructivistas de Rawls y Dworkin: "ambos sostienen unos principios morales que no sólo son justificativos y básicos del contrato social, sino que continúan fundamentando todo lo que se construya al desarrollarlo y ponerlo al día. No construyen ni a Leviathan ni a Demos ni tampoco un sistema formal de producción de normas o pirámide jurídica, sino un sistema para comprobar los principios inherentes a una constitución que, por ende, sirven para interpretarla, así como a todas las leyes dimanantes y para orientar sus sentencias a los jueces. Pero su modelo constructivo es como una bisagra entre unos principios intuidos y las realizaciones jurídicas comprobadas por mediación de su método del equilibrio y del avance y retroceso entre las adaptaciones y la convicción de nuestras intuiciones, hasta lograr la mejor adecuación posible. No se elabora éste deductivamente desde los principios, como hacía la Escuela del derecho natural y de gentes, ni dialécticamente entre normas, valores y naturaleza de las cosas, ni existencialmente, ni tampoco en un ir y venir desde los primeros principios de la naturaleza del hombre a las cosas y de la naturaleza de éstas (la rerum natura) a los principios, en constante interacción. Sino que, como en la física, se construye un modelo, una hipótesis de contrato social que sirve a modo de andamio para construir desde él, las estructuras jurídicas y concretar sus principios y leyes y adjudicar los derechos" $"$.

Concluye que "estamos, pues, ante ideologías y, como tales, poiéticamente constructivas, según el modelo que se programe, aunque se trate de corregir continuamente su desarrollo por el método del equilibrio y del avance y retroceso propuesto por el mismo Rawls" ".

No es satisfactoria, en mi opinión, la crítica de Vallet de Goytisolo a estos autores. Ciertamente detecta en ellos el relativismo y positivismo que todavía subsiste en los juristas de los valores, y la especie de constructivismo ético de Rawls y Dworkin. Sin embargo, no advierte las diferencias relevantes entre Rawls y Dworkin ni cómo Dworkin, a pesar del contenido liberal de sus conclusiones, adopta una posición iusnaturalista sobre el derecho y el razonamiento juridico: los "principios" que guían la labor judicial para alcanzar la respuesta correcta (justa) cumplen la misma función en el pensamiento de Dworkin que en la preocupación

hacia el 'Tistado de los jueces'. En ese sentide, no tiene lugar ninguna semejanza con 'lo justo por naturaleza', Es decir, no es ninguna promoción de la justicia el que alguien haga suyas las ideas filosófico-valónicas de otro cualquiera. P'recisamente ese no depende del arbitrio de nadie, y no puede, por consiguiente, ser objeto de una regulación juridica. 1) a ahi que no deberian jugar ningún rol en la calificación juridica de un hecho la valoración de sus motivos en base a su altura moral. Y cuando digo aqui 'deberian', lo hago en base a reflexiones iusnaturalistas elementales, de las cuales surge que es injusto prescribir y jusgar juridicamente algo cuya realización no depende del arbitrio de nadie: por ejemplo, convicciones religosas, convicciones politicas o escalas de valores. Lo justo natural se relaciona más bien primariamente con la prescripción de procedimientos para aquellos casos en los cuales no se puede encontrar una concordancia sobre valores": Robert Spaemann, "Die Aktualität des Naturrechts", en Robert Spaemann, Philophische Essays, Reclam, Stuttgart, 1994, 61-63. La traducción es de Carlos Isler.

30

VALLEI DE: GOYTISOI.O; Metodología de las leyes, 443-444,

31 Ibid. 444 
clásica por una ley natural, a saber, sustraer a la arbitrariedad del poder un núcleo indisponible de derecho. Un juicio más matizado sobre estos autores tendría en cuenta de dónde vienen, es decir, cómo la reciente teoría del derecho se ha ido acercando al reconocimiento de verdades elementales recibidas en la tradición de la teoría del derecho natural. De todos modos, el pensamiento de Vallet de Goytisolo es un botón de muestra de cómo la teoría jurídica hispana se ha anticipado a muchos de los desarrollos aparentemente novedosos de la teoría analítica del derecho.

\section{Los principios tradicionales de cada país}

Vallet de Goytisolo sostiene que los principios tradicionales de una cultura o sistema jurídico reciben el influjo de principios éticos y de principios políticos, "pero les dan una versión propia, adecuada a sus peculiares circunstancias y cernida en su propia historia. Asi lo vemos en la antigua Grecia, donde se conjugaba lo ético con lo político propio, en que eran educados todos los ciudadanos, quienes lo vivían y enseñaban a las generaciones siguientes" $"$. De este modo, cabe distinguir, además de los primeros principios y de los preceptos secundarios de la ley natural, los preceptos de tercer grado que, según Tomás de Aquino, pertenecen a la ley natural pero de diverso modo. En consecuencia, el derecho natural se concreta de diversa manera según tiempo y lugar, sin contradecir los principios inmutables . Estas concreciones son los "principios tradicionales de cada nación", que, aunque - al decir de Larenz - no son suficientes para enfrentar todos los problemas jurídicos actuales, tienen un valor innegable para plantear vías de solución. Especialmente "la concepción tradicional española que vemos en Torras y Bages, Vásquez de Mella, Salvador Minguijón, F. Elías de Tejada, Rafael Gambra y F. Puy, Alvaro D'Ors" es apta para enfrentar los problemas nuevos. "Precisamente el progreso - como ha escrito Collingwood-consiste en conservar las soluciones de aquellas cuestiones resueltas por las generaciones anteriores y en dominar algunas de las que ellas no pudieron resolver. No podemos comenzar en cada generación a construir desde la primera piedra, desde cero. Incluso muchas cuestiones nuevas y acuciantes para las cuales la tradición viva no nos trae solución, podemos hallarlas resueltas, ${ }_{34}$ por lo menos un camino para resolverlos en derechos puramente históricos" $"$.

Vallet de Goytisolo defiende una posición tradicionalista, muy optimista respecto de la fecundidad de los principios tradicionales españoles. No nos interesa, en este trabajo, esta particular valoración, sino advertir que estos principios, que no son de derecho natural sino concreciones históricas cambiantes, también han sido

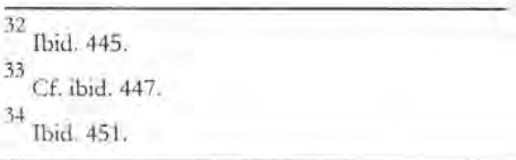


considerados en la discusión de la filosofia analítica como verdaderos principios (históricos, positivos) orientadores del razonamiento judicial, como ha mostrado Neil MacCormick ${ }^{35}$. En consecuencia, la discusión sobre el estatus de los principios jurídicos no exige - ni en el contexto de la filosofía jurídica española ni en el de la teoría anglosajona- una opción entre declararlos "principios morales" o "principios meramente positivos", pues los dos tipos de principios integran el sistema de judicación vigente ${ }^{36}$.

\section{Principios de la ley natural y derechos humanos}

Los sistemas jurídicos contemporáneos, especialmente en sus constituciones escritas, "formalizan, junto con principios políticos, verdaderos principios éticojurídicos, efectuándolo muchas veces en forma de reconocimiento constitucional de 'derechos humanos" ${ }^{37}$. Nuestro autor se remite, nuevamente, a los estudios de Dworkin, que parecen mostrar una cierta equiparación entre "principios" y "derechos humanos". Los denominados derechos humanos "no son normas que deban aplicarse de modo monolineal, sin atender a nada más. En realidad, son expresión de principios, más o menos positivizados, que pueden entrar en contradicción con otros, en general, $y$, especificamente, con los concurrentes que actúen a favor de otras personas. Como tales principios, se hallan en interacción con la naturaleza de la cosa, en relación a la cual se manifiesten, y deben concretarse. Además, y por ello, pueden imponer al propio favorecido correlativos deberes, de cuyo cumplimiento dependerá la aplicación, a su favor, de cuanto le beneficie. Es decir, en resumen, no constituyen excepciones dentro de la clase de los principios ético-jurídicos" $"$.

Los principios de la ley natural —o su expresión en forma de "derechos humanos"- requieren de concreción, como hemos visto. Lo "justo por

\footnotetext{
35

Cf. MACCORMICK, Neil; Legal Reasoning and Legal Theory, Oxford University Press, Oxford, 1997 (1² ed. 1978), especialmente $223 \mathrm{ss}$.

36

Cf. VALLET DE GOYTISOLO; Metodología de las leyes, 451-452. Afirma, expresando así el lamento por el abandono de los principios tradicionales: "hemos de reconocer que la Constitución de 1978 y las reformas legislativas posteriores no se mantienen dentro de muchos de estos principios y en especial de los más esenciales. El deterioro social y humano que venimos sufriendo no es ajeno a esta ruptura" (ibid, 452).

${ }^{37}$ Ibid 460 .

38

Cf. ibid. $460(-461$.

39 Ibid. 475. VALLET DE GOYTISOLO comparte la crítica de Villey a la ideologia de los derechos humanos y, en consecuencia, a la expresión misma. Cf. ibid. 463. Sin embargo, también con Villey, no se ciega a reconocer su valor frente al positivismo dominante: "ese encadenamiento del derecho al positivismo normativista dejaba algunos portillos abiertos al derecho natural. Uno, juridico, dimanante de la propia interpretación de la ley y de la necesidad de integrar sus lagunas, y los otros dos, previos a ella —en cuanto salvaguardados por el propio 'pacto social'- constituidos por los denominados derechos humanos y por la libertad de la propiedad dinámicamente considerada. Basados ambos en la existencia de un originario derecho natural y en que no tan sólo no fueron cancelados en el pacto, sino que con c̀ se trataba de defenderlos" (Juan Vallet de Goytisolo, Metodologia juridica, 344).
} 
naturaleza" de Aristóteles ha de determinarse "en concreto" del derecho natural racionalista fue intentar elaborar un orden abstracto aplicable en todos tiempos y lugares, despreciando la propia realidad histórica de los individuos. Frente a ello, nuestro autor recalca que una correcta concepción del derecho natural, tal como emana de la naturaleza de las cosas, debe tener en cuenta al hombre concreto". "Y esa relatividad circunstancial ya la hallamos precisada por San Isidoro de Sevilla (Etimologías, 5, 21) al decir que 'la ley debe ser posible, conforme con la naturaleza, apropiada a las costumbres del país'; y por Santo Tomás $(S . T h$, I-II, 95, 3) quien expone que la ley ha de ser 'posible, conforme a la naturaleza', en el sentido de estar en 'conformidad con la disciplina humana', 'según las facultades de quienes hayan de practicarla', 'apropiada a las costumbres del país' y "conveniente al lugar"" ${ }^{42}$.

Las exigencias concretas de la justicia suponen circunstancias históricas que configuran el bien común. El bien común sirve como pauta para determinar qué preceptos de la ley natural son exclusivamente éticos, y cuáles son jurídicos: "Notemos que así como la virtud de la justicia, en cuanto virtud general (...) está siempre ordenada al bien común, este mismo bien común excluye en algunos casos su exigencia jurídica humana" ${ }^{43}$. En consecuencia, en tres sucesivas exclusiones nuestro autor restringe los preceptos de ley natural que son jurídicos, en el sentido de exigibles mediante el sistema de derecho positivo. Primero, hay "unos preceptos de la ley natural que no son jurídicos porque no se refieren a la justicia"; luego, "otros que tampoco lo son, pues aun refiriéndose a la justicia, no afectan inmediatamente al bien común humano"; y finalmente "otros que, aun refiriéndose al bien común humano, este mismo bien requiere que no se impongan jurídicamente para no impedir otros mayores bienes o no producir un mayor mal" (conforme a la doctrina tomista sobre la tolerancia). "El bien común es la pauta para que el derecho natural humano urja al derecho civil, o positivo humano en sentido lato, a fin de que exija o no jurídicamente, conforme este bien común pide, el cumplimiento de lo que moralmente es de justicia" ${ }^{45}$.

\section{Conclusión}

En la concepción que tiene Vallet de Goytisolo de la labor del jurista adquieren enorme importancia los principios (especialmente los ético-jurídicos o de

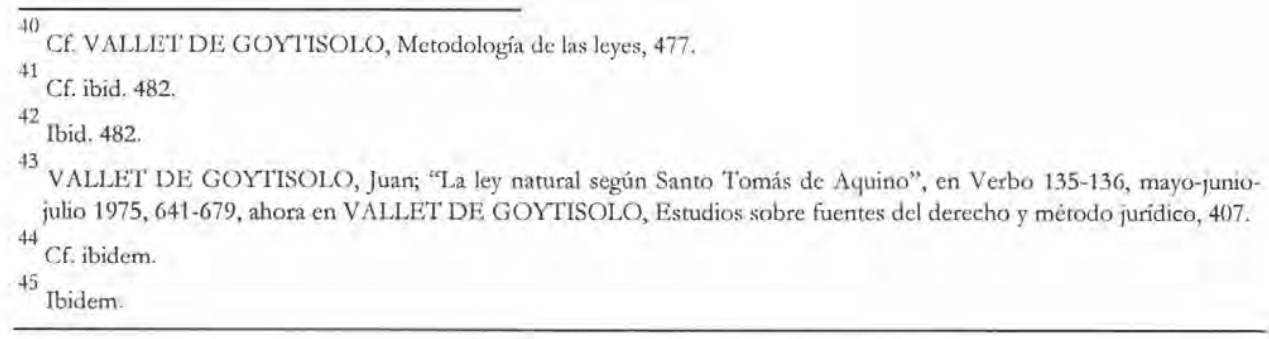


derecho natural, y la equidad), pues priman sobre, o modifican el tenor literal de las leyes positivas. Esta tesis escandalizaba tanto a los positivistas legalistas como a los normativistas que concedían al juez solamente una discrecionalidad marginal o intersticial. Sin embargo, la reciente teoría analítica del derecho está propugnando una idea muy parecida: los jueces pueden ir más allá de las normas positivas, ya sea porque deben encontrar una única respuesta correcta apoyándose en principios (Dworkin) ya porque gozan de discrecionalidad ("positivista") incluso en los casos ordinarios (no solamente en los "casos difíciles"). Un representante del más puro iusnaturalismo clásico (como lo entendía Tomás de Aquino) coincide, pues, en conclusiones importantes con los representantes actuales de la teoría analítica del derecho, aunque éstos se presenten como enfrascados en pseudopolémicas sobre qué es y qué no es "positivismo jurídico". Por eso interesa tanto un autor como Vallet de Goytisolo, que no estudió en detalle a los autores analíticos ni influyó en ellos. Es como un campo de prueba de una tesis iusfilosófica que exploro desde hace un tiempo, al menos como hipótesis: que la teoría analítica del Derecho está regresando, poco a poco, a una concepción iusnaturalista clásica, al menos en aspectos fundamentales .

${ }^{46}$ Cf. FINNIS, John; "Natural Law: The Classical Tradition", 26. 